\title{
Exotic manganese dioxide structures in niobium oxides capacitors
}

\author{
C. Nico*, M.R.N. Soares*, M. Matos**, R. Monteiro**, M. P. F. Graça*, T. Monteiro*, F. M. Costa* \\ and M. A. Valente* \\ * I3N - Department of Physics, University of Aveiro, Campus de Santiago, 3810-193 Aveiro, Portugal \\ ** KEMET Electronics, R Werner V Siemens 1 7005-639 Évora, Portugal
}

The production of a Tantalum solid electrolytic capacitor requires the impregnation of $\mathrm{MnO}_{2}$ by pyrolysis in one of the several manufacturing steps. It has been reported [1-3] that niobium oxides are a good alternative, presenting potentially better dielectric properties and a better cost effectiveness. Thus, it is important to study the conditions and the effect of the $\mathrm{MnO}_{2}$ impregnation on niobium oxide in order to understand and optimize the parameters of this process. The morphology and microstructure of the anode is one of the most important aspects that interfere with the dielectric properties of the capacitor. In this work, it is presented a study of the morphology and microstructure of different niobium oxide anodes after electrochemical oxidation $\left(\mathrm{NbO} / \mathrm{Nb}_{2} \mathrm{O}_{5}\right.$ core-shell grain structure), and after $\mathrm{MnO}_{2}$ impregnation with different pyrolysis temperatures. This impregnation is made by dipping the anodes, with the $\mathrm{NbO} / \mathrm{Nb}_{2} \mathrm{O}_{5}$ core-shell structure, in a slurry of $\mathrm{Mn}\left(\mathrm{NO}_{3}\right)_{2}$. Heating this slurry while the anode is dipped, will lead to a pyrolysis reaction where the liberation of $\mathrm{NO}_{2}$ occurs as a gas, and where the product $\mathrm{MnO}_{2}$ solidifies around the grains.

It is observed a uniform cover of the $\mathrm{NbO} / \mathrm{Nb}_{2} \mathrm{O}_{5}$ grains with $\mathrm{MnO}_{2}$, which presented an average grain size between 100 and $200 \mathrm{~nm}$ with high coalescence. The most interesting result is related with the samples with the highest pyrolysis temperature $\left(\mathrm{T}=270^{\circ} \mathrm{C}\right)$. In the inner centre of these samples it is observed several $\mathrm{MnO}_{2}$ particles with a hexagonal pyramid shape, figure 1. At the surface, needle and mushroom shapes morphologies were identified. These exotic morphologies are probably related to the high viscosity of the $\mathrm{Mn}\left(\mathrm{NO}_{3}\right)_{2}$ slurry and to the high pyrolysis temperature.

These structures may have an undesirable morphology for this kind of application since it leads to difficulties on the following processing steps given its rugosity and inhomogeneity at the surface. For other purposes, such as nanoparticles manipulation, templates or electronic devices like antennas, it may be interesting to reproduce and to study these structures. For the application in capacitors, these results suggest that we should decrease the pyrolysis temperature, and/or try slower heating rates.

\section{References}

1. C. Nico et al., The Journal of Physical Chemistry C 115: 4879-4886, 2011

2. M.R.N. Soares et al., Journal of European Ceramic Society 31: 501-506, 2011

3. H. Störmer, Journal of European Ceramic Society 29: 1743-1753, 2009 

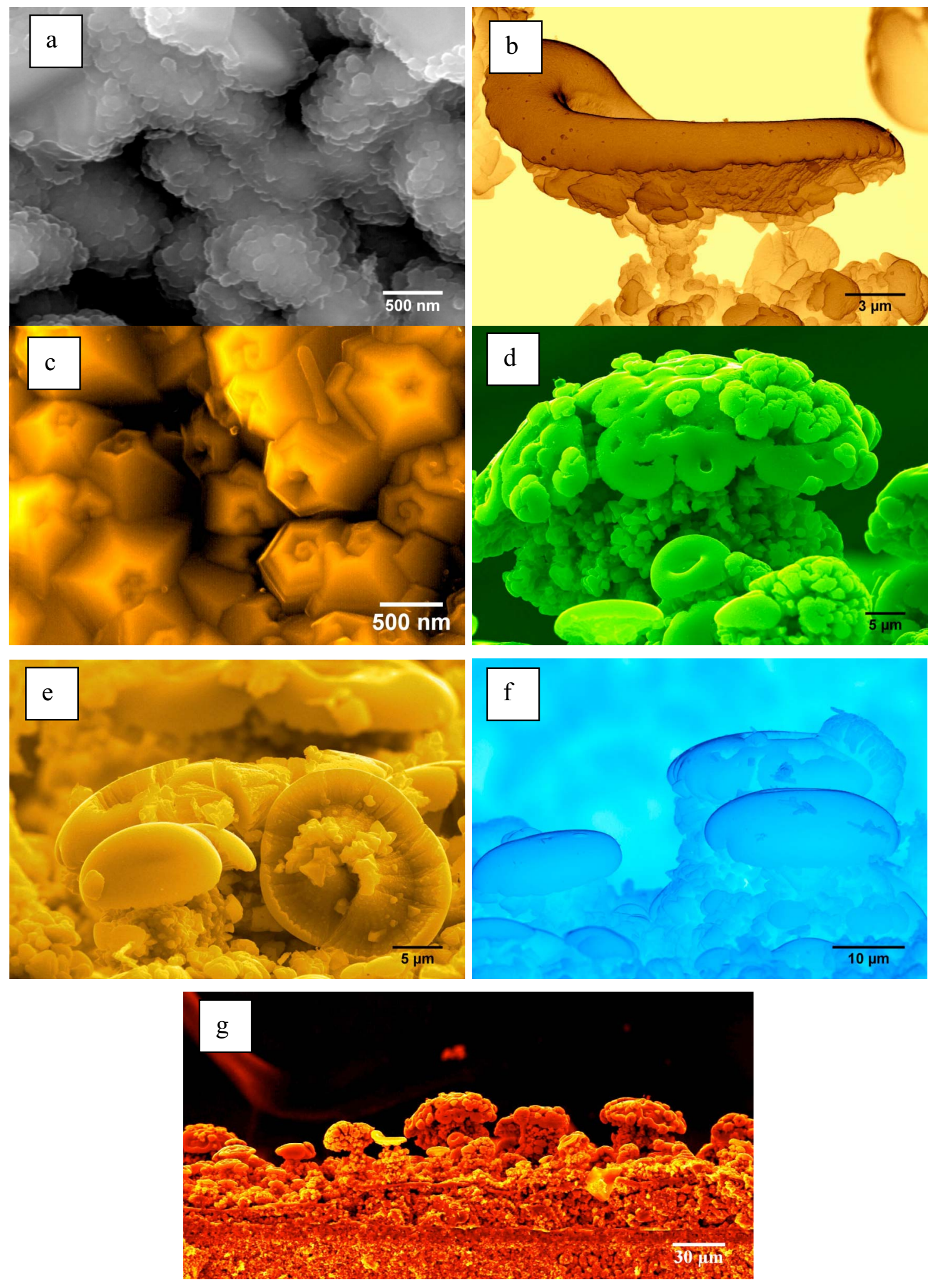

Figure 1. Homogeneous coverage of the $\mathrm{NbO} / \mathrm{Nb} 2 \mathrm{O} 5$ with $\mathrm{MnO} 2$ nanoparticles (a); Mushroom shape morphology of $\mathrm{MnO} 2$ at the anodes surface with a pyrolysis temperature of $\mathrm{TPy}=270{ }^{\circ} \mathrm{C},(\mathrm{b}, \mathrm{d}-\mathrm{g})$ and the hexagonal pyramids of $\mathrm{MnO} 2$ in the inner centre (with computational colour manipulation) (c). 